\title{
IMPLEMENTASI E-LEARNING MATA PELAJARAN PEMELIHARAAN MESIN SEPEDA MOTOR DI SMK BERBASIS ANDROID
}

\author{
Irfan Khurri Fikri ${ }^{1}$, Dentik Karyaningsih ${ }^{* 2}$, Akip Suhendar ${ }^{3}$ \\ ${ }^{1,2,3}$ Program Studi Teknik Informatika Fakultas Teknologi Informasi Universitas Serang Raya \\ Jln. Raya Cilegon Serang - Drangong Kota Serang \\ 1oryza4444@gmail.com \\ ${ }^{2 *}$ karya.tiek@gmail.com \\ 33akip.suhendar@gmail.com
}

\begin{abstract}
Abstrak
E-Learning adalah salah satu hal yang harus di terapkan di sekolah, karena pada era pandemi seperti ini, murid dan guru tidak dapat bertatap muka secara langsung, karena harus mematuhi protokol-protokol kesehatan yang telah dihimbau oleh pemerintah, baik siswa maupun guru tentu saja kesulitan dalam melakukan kegiatan belajar mengajar khususnya untuk mata pelajaran yang sifatnya praktek, terlepas daripada itu E-Learning merupakan salah satu hal yang dapat diterapkan untuk membantu kegiatan belajar mengajar tetap berjalan. Mata pelajaran Pemeliharaan Mesin Sepeda Motor merupakan mata pelajaran praktek pada saat pandemi mengalami kesulitan dalam proses belajar, sehingga penelitian ini untuk membantu pelaksanaan pembelajaran secara online berbasis android. Metode yang digunakan dalam penelitian ini adalah metode waterfall dengan perancangan menggunakan UML(Unified Modeling Language). Aplikasi E-Learning ini dibuat dengan menggunakan bahasa pemrograman Dart, Php dan Mysql sebagai basis datanya.
\end{abstract}

Kata kunci: E-Learning, Android,Mata Pelajaran Praktek

\section{Pendahuluan}

Kegiatan belajar mengajar secara daring sudah lama di laksanakan di berbagai tempat di Indonesia, namun pada awal tahun 2020 suatu wabah mulai melanda hampir di seluruh negri, wabah tersebut dikenal dengan covid-19, banyak sektor yang terdampak ketika wabah ini menyerang salah satunya yaitu sistem pembelajaran yang dilakukan di sekolah-sekolah. SMK PRISMA CITRA NUSANTARA masih belum memiliki teknologi untuk menanggulangi masalah physical distancing dalam kegiatan belajar mengajar, guna menanggulangi masalah saat ini, E-Learning merupakan salah satu cara untuk mempermudah kegiatan belajar mengajar secara daring menggunakan internet. Perkembangan teknologi membuat kebutuhan terhadap suatu konsep dan prosedur belajar mengajar berbasis TI tidak terelakkan. Konsep tersebut biasa dikenal dengan E-Learning.[1] Penggunaan media elektronik di bidang pendidikan telah mengenalkan sistem E-Learning yang memungkinkan para pendidik melakukannya belajar kapan saja dan di lokasi yang berbeda, E-Learning mengacu pada penggunaan teknologi dalam pembelajaran yang berbeda kegiatan dan untuk membantu orang untuk belajar dari jarak jauh.[2]

Mata pelajaran Pemeliharaan Mesin Sepeda Motor (PMSM) merupakan salah satu mata pelajaran yang di pelajari di SMK PRISMA CITRA NUSANTARA, mata pelajaran tersebut berada di jurusan Teknik dan Bisnis Sepeda Motor, mata pelajaran tersebut bersifat praktik, yang dimana harus ada interaksi antara guru dan murid, guru menjelaskan dan memperagakan kemudian diikuti siswa sambil di praktikkan. Beberapa penelitian yang dilakukan dalam pelaksanaan pembelajaran online diantaranya [3] Efektivitas Penggunaan Google Form Dalam Pembelajaran Daring Pada Mata Pelajaran Pemeliharaan Mesin Sepeda Motor menggunakan penelitian kualitatif untuk mengetahui efektivitas penggunaan Google Form dalam pembelajaran daring Dengan hasil ini Google Form dapat digunakan sebagai salah satu media pembelajaran pada masa pandemi COVID-19 sebagai 
alternatif pengganti pembelajaran tatap muka. Penelitian[4] Perancangan E-Learning pada SMK Negeri 1 Bandung bahwa dengan adanya e-learning, guru dapat memberikan materi maupun tugas yang disimpan secara digital dan dapat diakses kapanpun dan dimanapun. Penelitian[5] Perancangan Sistem Informasi E-Learning Pada SMK Syubbanul Wathon Tegalrejo Magelang Metode ini memudahkan para guru untuk dapat menyampaikan materi pelajaran, memberikan kuis secara online, memberikan info sekolah dengan lebih cepat, pengumpulan tugas siswa secara online, dan melakukan konsultasi kepada siswa kapanpun dan dimanapun tanpa ada batas ruang dan waktu.

Dari latar belakang tersebut, penulis tertarik untuk melakukan penelitian terkait implementasi E-Learning mata pelajaran Teknik Kendaraan Ringan berbasis mobile android di SMK PRISMA CITRA NUSANTARA yang bertujuan untuk Memudahkan kegiatan belajar mengajar di SMK. Android merupakan perangkat bergerak pada sistem operasi untuk telepon seluler yang berbasis linux.[2] Metode yang digunakan dalam penelitian ini adalah metode waterfall dengan perancangan menggunakan UML(Unified Modeling Language). Aplikasi E-Learning ini dibuat dengan menggunakan bahasa pemrograman Dart, Php dan Mysql sebagai basis datanya.

\section{Metodologi PENELITIAN}

Pada penelitian ini penulis menggunakan jenis penelitian terapan (Reseach Applied) yang bertujuan untuk memudahkan implementasi sistem E-Learning di SMK Prisma Citra Nusantara guna mempermudah akses materi serta berjalannya kegiatan belajar mengajar secara online. Dalam penelitian implementasi E-Learning di smk terdapat beberapa tahapan, yaitu:

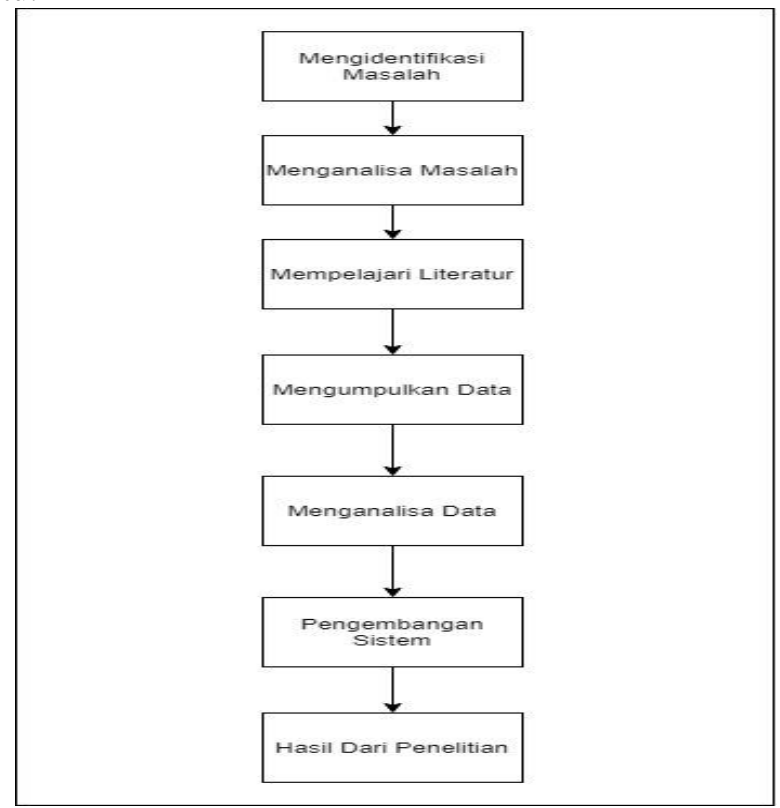

Gambar 1. Tahapan Penelitian

\section{A. Identifikasi Masalah}

Pada tahap ini dilakukan identifikasi suatu masalah pada kegiatan belajar mengajar pada SMK Prisma Citra Nusantara. Dengan demikian, diharapkan peneliti dapat mengenali suatu kendala yang diketahui dari permasalahan yang ada.

\section{B. Menganalisa masalah}

Di tahap ini dengan menganalisa masalah yang ada, diharapkan mampu untuk menentukan solusi terbaik guna menangani masalah tersebut.

\section{Mempelajari Literatur}

Pada tahapan ini dilakukan pencarian landasan-landasan teori yang diperoleh dari berbagai buku, Jurnal dan juga internet untuk melengkapi konsep dan teori.

\section{Mengumpulkan Data}

Di tahap ini dilakukan pengumpulan data guna memperoleh data untuk dianalisis, sehingga dapat mempermudah menemukan permasalahan-permasalahan yang ada. Adapun hasil yang diharapkan dari penelitian ini ialah untuk mendapatkan solusi terbaik dari permasalahan tersebut. Pengumpulan data dilakukan dengan 2 cara, yaitu pengamatan langsung (Observasi) di lingkungan sekolah dan kuesioner kepada kepala sekolah, guru dan siswa

\section{E. Analisis Data}

Data yang telah dihimpun untuk mendukung proses penelitian ini. Adapun jenis data yang dihimpun antara lain : data informasi dan nilai siswa, kurikulum yang digunakan, data materi mata pelajaran Pemeliharaan Mesin Sepeda Motor (PMSM). Sumber data yang diperlukan berasal dari hasil kuesioner dan observasi yang dilakukan oleh peneliti secara langsung pada SMK Prisma Citra Nusantara

\section{F. Pengembangan Sistem}

Pada tahap ini dilakukan pengembangan sistem pembelajaran berbasis e-learning dengan bahasa pemrograman PHP dan DBMS MySQL sedangkan metode pengembangan sistem yang digunakan adalah metode model waterfall (air terjun). Adapun gambar model waterfall (air terjun) seperti diperlihatkan pada Gambar 2.

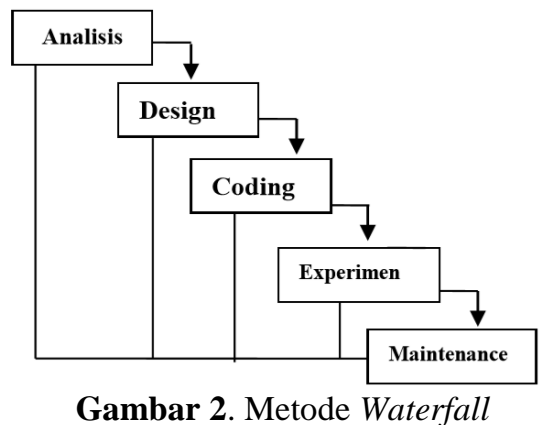

1) Analisis

Proses pengumpulan data yang dilakukan secara intensif untuk menspesifikasikan kebutuhan perangkat lunak agar dapat dipahami, perangkat lunak seperti apa yang dibutuhkan oleh user.

2) Design 
Pada tahap ini dilakukan perancangan interface dan model aplikasi menggunakan UML(Unified Modeling Language) diantaranya Use case Diagram, Class Diagram serta Activity Diagram.

3) Coding

Pada tahap ini sistem yang telah dirancang, diimplementasikan dengan menggunakan bahasa pemrograman yaitu DART, PHP dan MySQL, kemudian dilakukan pengujian terhadap tiap-tiap unit atau modul yang telah dibuat.

\section{4) Experiment}

Dilakukan pengujian secara keseluruhan agar software yang dikembangkan bebas dari error dan hasilnya sesuai dengan kebutuhan yang sudah didefinisikan sebelumnya. Pengujian ini bertujuan untuk menjamin kualitas website. Untuk testing alat yang digunakan adalah Emulator android (AVD) dan Black Box testing.

5) Maintenance

Tahap ini dilakukan jika diperlukannya perbaikan pada sistem, serta juga untuk pemeliharaan sistem agar selalu bisa di akses setiap saat.

\section{HASIL DAN PEMBAHASAN}

Dalam rancangan sistem penelitian ini menggunakan metode UML (Unified Modeling Language).

\section{A. Use case Diagram}

Diagram use case merupakan Pemodelan yang penting dalam UML, untuk menjelaskan aspek fungsionalitas sistem, adalah pemodelan use case. Use case dideskripsikan secara tekstual dalam bentuk use case scenario untuk menjelaskan interaksi yang terjadi antara aktor dengan sistem. Selanjutnya, use case diilustrasikan secara visual dalam bentuk use case diagram untuk menggambarkan konteks dari sistem yang dikembangkan[6]. Terdapat tiga(3) aktor pada use case tersebut yaitu siswa,admin dan guru.

Berikut ini adalah diagram use case dari aplikasi ini :

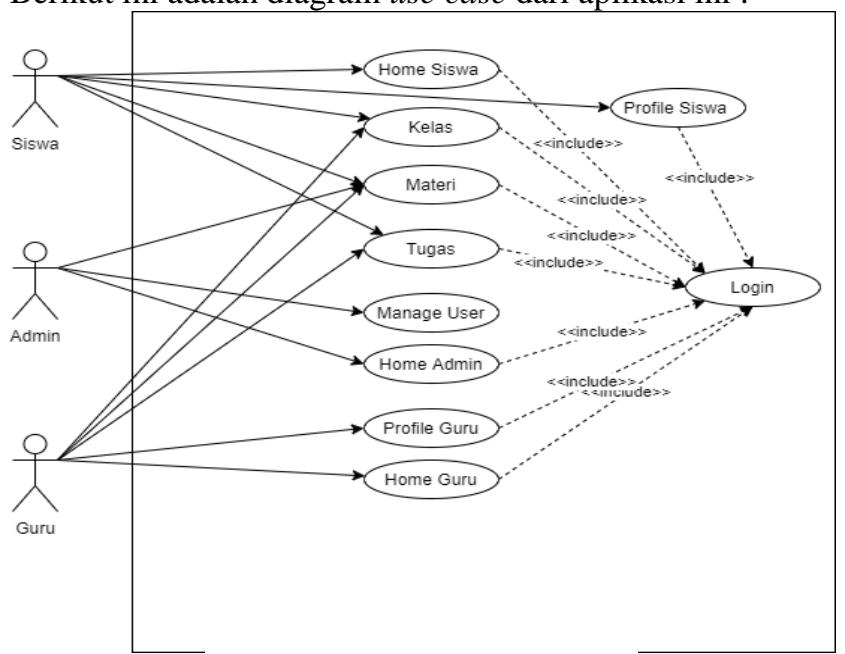

Gambar 3. Use case Diagram

\section{B. Class Diagram}

Class Diagram mendeskripsikan jenis - jenis obyek dalam sistem dan berbagai macam hubungan statis yang terjadi[7]. Pada diagram class ini akan menerangkan relasi antara tabel dalam database yang digunakan pada aplikasi, dibawah ini adalah class diagram dari aplikasi.

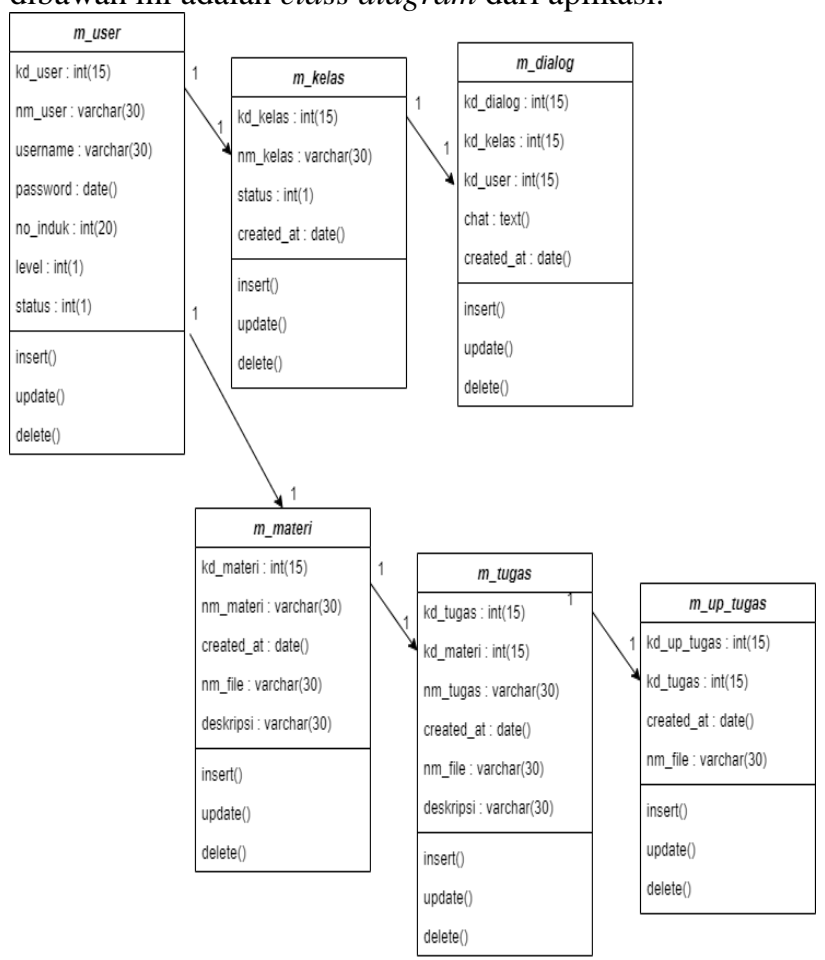

Gambar 4. Class Diagram

\section{Activity Diagram}

Activity Diagram menggambarkan workflow (aliran kerja) atau aktivitas dari sebuah sistem atau proses bisnis. dan flowchart. [8]

1). Activity Diagram Siswa

Pada activity diagram home siswa, Ketika siswa telah berhasil melakukan login pada halaman login, sistem akan langsung membawa ke halaman home siswa, kemudian siswa memilih menu kelas, lalu siswa mengikuti proses belajar mengajar yang dilakukan pada halaman kelas, jika guru memberi tugas maka siswa akan mengunduh tugas tersebut, dan jika tidak maka siswa boleh untuk melakukan logout, karna pemberian tugas akan diberikan Ketika di ahir kegiatan pembelajaran. Berikut activity diagram siswa: 


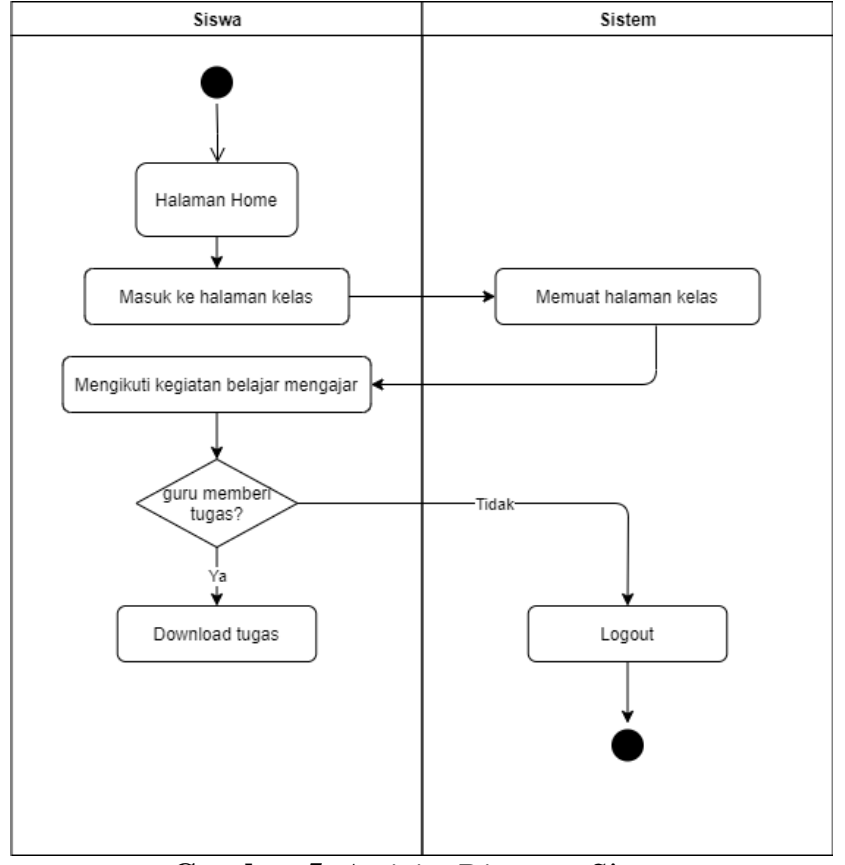

Gambar 5. Activity Diagram Siswa

2). Activity diagram guru

Pada diagram activity guru, Ketika guru telah berhasil melakukan login maka guru akan menuju halaman home, lalu memilih kelas kemudian melakukan kegiatan belajar mengajar, jika guru ingin memberi tugas maka guru akan mengupload tugas pada halaman tugas kemudian akan disimpan ke dalam database, jika tidak maka guru akan mengecek kehadiran siswa lalu selesai dan logout. Berikut activity diagram guru:

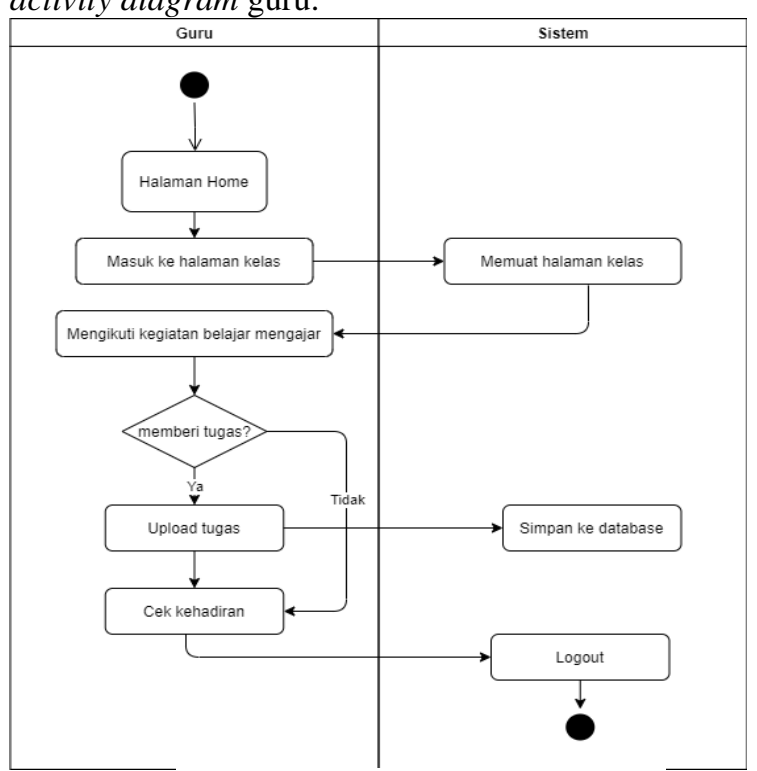

Gambar 6. Activity Diagram Guru

3). Activity Diagram Admin

Pada activity diagram admin, Ketika admin berhasil melalui proses login maka admin akan menuju halaman home admin, kemudian sistem akan menampilkan data user yang ada pada database, kemudian admin dapat melihat detail user Ketika mengklik tombol detail, lalu admin dapat mengubah, menghapus ataupun menambahkan data yang baru. Berikut activity diagram admin:

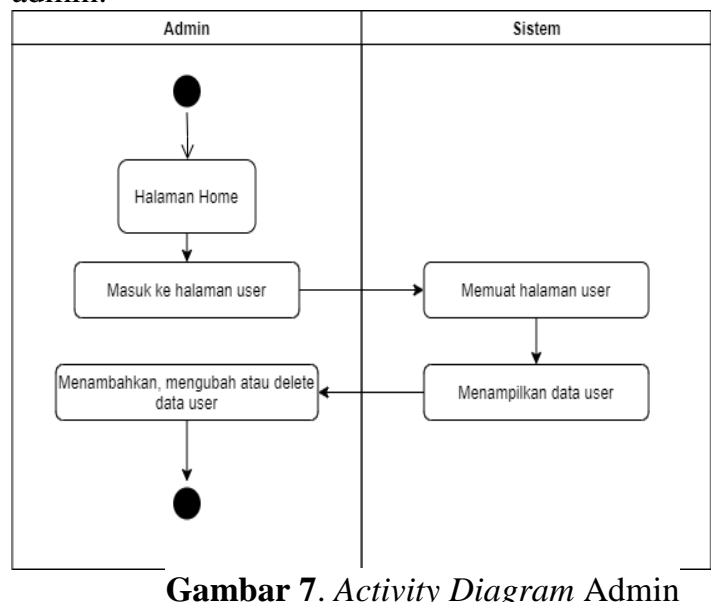

\section{B. Implementasi Sistem}

Implementasi ini dilakukan untuk menyelesaikan sistem yang ada pada perancangan sistem dan desain interface yang telah disetujui. Berikut adalah hasil implementasi sistem:

1). Halaman Login

Pada halaman ini sebelum user masuk ke dalam aplikasi maka user diharuskan untuk login terlebih dahulu, gambar dibawah ini adalah tampilan login.

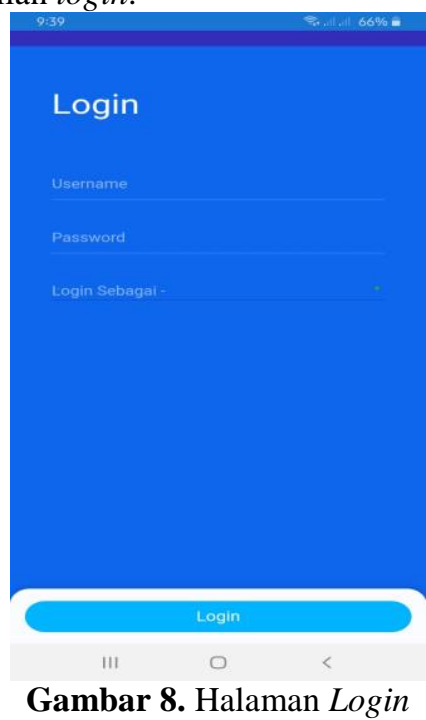

2). Halaman Guru

Pada tampilan halaman home akan menampilkan sejumlah menu menu yang dapat di akses oleh $u$ ser sesuai dengan posisi user, terlihat pada gambar dibawah ini. 


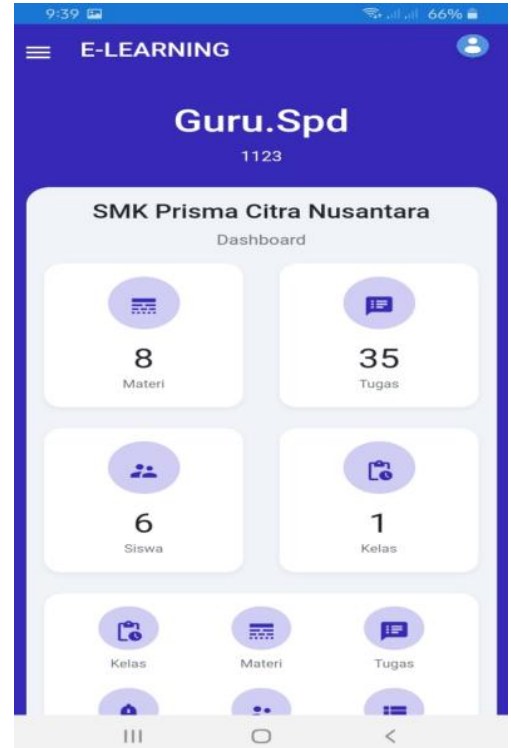

Gambar 9. Halaman Guru

3). Halaman Materi

Pada halaman ini Guru dapat menambahkan file materi yang kemudian akan di upload ke database, terlihat pada gambar dibawah ini.

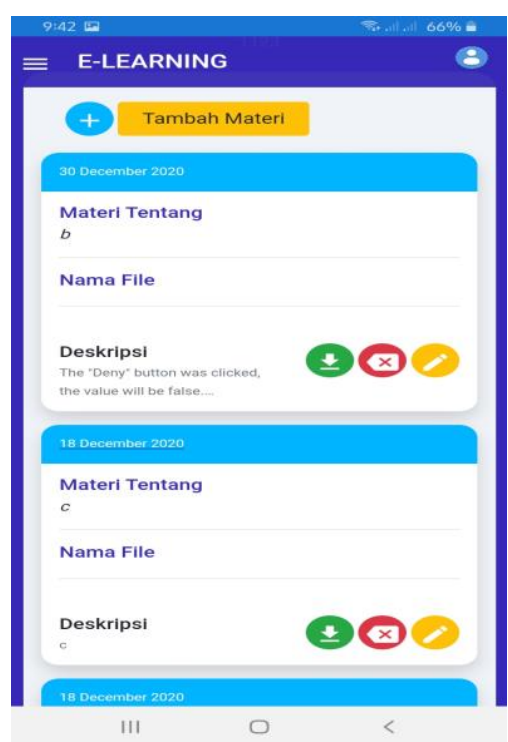

Gambar 10. Halaman Materi

\section{4). Halaman Kelas}

Pada halaman ini siswa dan guru dapat berinteraksi dengan mengirim text atau pesan pada kolom yang telah disediakan, terlihat pada gambar dibawah ini:

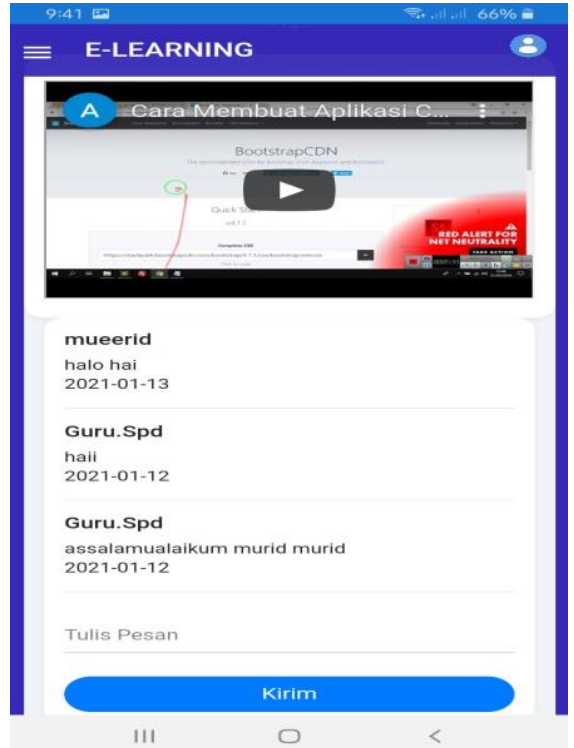

Gambar 11. Halaman Kelas

5). Halaman Menu

Setelah berhasil melakukan login maka sistem akan menampilkan menu yang sesuai dengan posisi atau level user, terlihat pada gambar dibawah ini:

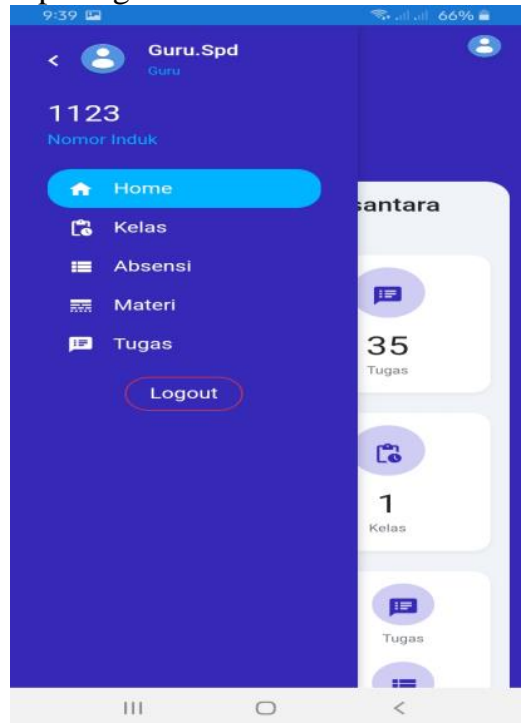

Gambar 12. Halaman Menu

6). Halaman Home Siswa

Setelah berhasil melakukan login maka sistem akan menampilkan menu yang sesuai dengan posisi atau level user, terlihat pada gambar dibawah ini: 


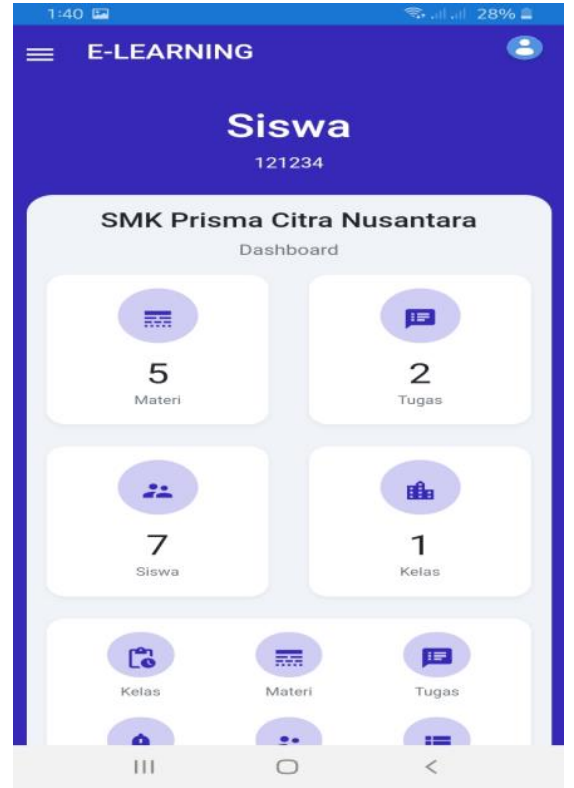

Gambar 13. Halaman Home Siswa

7). Halaman Home Admin

Setelah berhasil melakukan login maka sistem akan menampilkan menu yang sesuai dengan posisi atau level user, terlihat pada gambar dibawah ini:

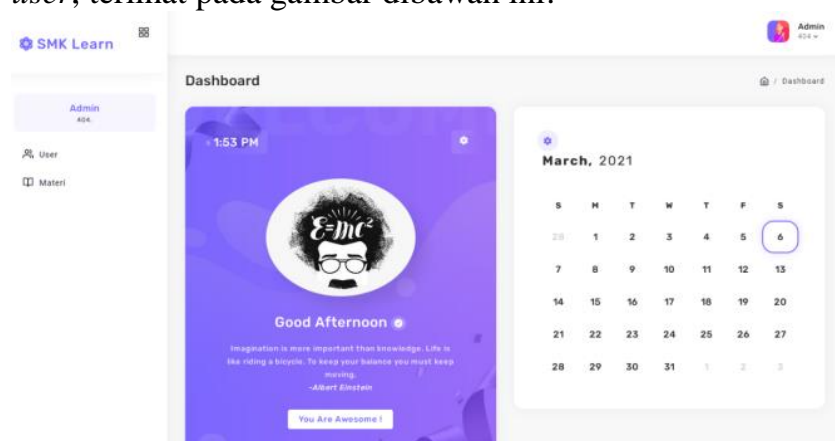

\section{Pengujian Sistem}

Pengujian sistem yang dilakukan pada SMK Prisma Citra Nusantara (SMK PCN), dengan menggunakan metode Black Box testing merupakan pengujian kualitas perangkat lunak yang berfokus pada fungsionalitas perangkat lunak.[9] Cara pengujian ini di lakukan pada aplikasi yang telah dibuat sesuai dengan kebutuhan, SMK Prisma Citra Nusantara (SMK PCN). Pada kesempatan tersebut, Bapak Ahmad Ruri Rosadi, S. Pd selaku wakil kepala kurikulum, bersedia untuk menguji aplikasi $E$ Learning berbasis android tersebut. Hasil pengujian black box testing yaitu sebagai berikut:

Tabel 1. Pengujian Black Box Testing Login Guru

\begin{tabular}{|c|c|c|c|c|c|}
\hline $\begin{array}{c}\text { No } \\
\cdot\end{array}$ & $\begin{array}{c}\text { Skenario } \\
\text { Pengujian }\end{array}$ & $\begin{array}{c}\text { Test } \\
\text { Case }\end{array}$ & $\begin{array}{c}\text { Hasil Yang } \\
\text { diharapkan }\end{array}$ & $\begin{array}{c}\text { Hasil } \\
\text { uji }\end{array}$ & Kesimpulan \\
\hline 1. & $\begin{array}{c}\text { Username } \\
\text { dan } \\
\text { Password }\end{array}$ & $\begin{array}{c}\text { Usern } \\
\text { ame: } \\
\text { (koso }\end{array}$ & $\begin{array}{c}\text { Sistem akan } \\
\text { menolak dan } \\
\text { menampilkan }\end{array}$ & $\begin{array}{c}\text { Sesuai } \\
\text { yang } \\
\text { dihara }\end{array}$ & Valid \\
\hline
\end{tabular}

\begin{tabular}{|c|c|c|c|c|c|}
\hline & $\begin{array}{l}\text { tidak diisi } \\
\text { kemudian } \\
\text { klik Login }\end{array}$ & $\begin{array}{c}\text { ng) } \\
\text { Passw } \\
\text { ord: } \\
\text { (koso } \\
\text { ng) }\end{array}$ & $\begin{array}{c}\text { pesan "Harap } \\
\text { isi username } \\
\text { dan } \\
\text { password" }\end{array}$ & pkan & \\
\hline 2. & $\begin{array}{l}\text { Memasukk } \\
\text { an } \\
\text { username } \\
\text { dan } \\
\text { password } \\
\text { yang } \\
\text { sesuai lalu } \\
\text { klik } \\
\text { tombol } \\
\text { Login }\end{array}$ & $\begin{array}{c}\text { Usern } \\
\text { ame: } \\
\text { (guru) } \\
\text { Passw } \\
\text { ord: } \\
\text { (guru1 } \\
23 \text { ) }\end{array}$ & $\begin{array}{c}\text { Sistem } \\
\text { menerima } \\
\text { akses login } \\
\text { kemudian } \\
\text { menampilkan } \\
\text { halaman } \\
\text { utama Guru } \\
\text { atau User }\end{array}$ & $\begin{array}{l}\text { Sesuai } \\
\text { yang } \\
\text { dihara } \\
\text { pkan }\end{array}$ & Valid \\
\hline
\end{tabular}

Tabel 2. Pengujian Black Box testing halaman home guru

\begin{tabular}{|c|c|c|c|c|c|}
\hline $\begin{array}{c}\text { No } \\
\cdot\end{array}$ & $\begin{array}{c}\text { Skenario } \\
\text { Pengujian }\end{array}$ & $\begin{array}{c}\text { Test } \\
\text { Case }\end{array}$ & $\begin{array}{c}\text { Hasil Yang } \\
\text { diharapkan }\end{array}$ & $\begin{array}{c}\text { Hasil } \\
\text { uji }\end{array}$ & Kesimpulan \\
\hline 1. & $\begin{array}{c}\text { Menampilk } \\
\text { an data diri } \\
\text { guru } \\
\text { berdasarka } \\
\text { n login }\end{array}$ & $\begin{array}{c}\text { Data } \\
\text { diri } \\
\text { guru } \\
\text { belum } \\
\text { lengka } \\
\mathrm{p}\end{array}$ & $\begin{array}{c}\text { Sistem akan } \\
\text { menampilka } \\
\text { n pesan } \\
\text { "Data diri } \\
\text { belum di } \\
\text { lengkapi }\end{array}$ & $\begin{array}{c}\text { Sesuai } \\
\text { yang } \\
\text { dihara } \\
\text { pkan }\end{array}$ & Valid \\
& $\begin{array}{c}\text { Mengklik } \\
\text { tombol } \\
\text { Simpan }\end{array}$ & $\begin{array}{c}\text { Klik } \\
\text { tombo } \\
1\end{array}$ & $\begin{array}{c}\text { Sistem akan } \\
\text { menyimpan } \\
\text { data yang } \\
\text { telah } \\
\text { dilengkapi }\end{array}$ & $\begin{array}{c}\text { Sesuai } \\
\text { yang } \\
\text { dihara } \\
\text { pkan }\end{array}$ & Valid \\
\hline
\end{tabular}

Tabel 3. Pengujian Black Box testing halaman materi

\begin{tabular}{|c|c|c|c|c|c|}
\hline $\begin{array}{c}\text { No } \\
\text {. }\end{array}$ & $\begin{array}{c}\text { Skenario } \\
\text { Pengujian }\end{array}$ & $\begin{array}{l}\text { Test } \\
\text { Case }\end{array}$ & $\begin{array}{c}\text { Hasil } \\
\text { Yang } \\
\text { diharapka } \\
\mathbf{n}\end{array}$ & Hasil uji & $\begin{array}{c}\text { Kesimpul } \\
\text { an }\end{array}$ \\
\hline 1. & $\begin{array}{c}\text { Menambahk } \\
\text { an Materi }\end{array}$ & $\begin{array}{c}\text { Klik } \\
\text { tomb } \\
\text { ol }\end{array}$ & $\begin{array}{c}\text { Sistem } \\
\text { akan } \\
\text { menampilk } \\
\text { an form } \\
\text { yang harus } \\
\text { di isi }\end{array}$ & $\begin{array}{c}\text { Sesuai } \\
\text { yang } \\
\text { diharapk } \\
\text { an }\end{array}$ & Valid \\
\hline 2. & $\begin{array}{c}\text { Mengklik } \\
\text { tombol ubah } \\
\text { data }\end{array}$ & $\begin{array}{c}\text { Klik } \\
\text { tomb } \\
\text { ol }\end{array}$ & $\begin{array}{c}\text { Sistem } \\
\text { akan } \\
\text { mengarahk } \\
\text { an } \\
\text { kehalaman } \\
\text { form input } \\
\text { materi }\end{array}$ & $\begin{array}{c}\text { Sesuai } \\
\text { yang } \\
\text { diharapk } \\
\text { an }\end{array}$ & Valid \\
\hline
\end{tabular}




\begin{tabular}{|c|c|c|c|c|c|}
\hline & & & & & \\
\hline 3. & $\begin{array}{c}\text { Mengklik } \\
\text { tombol } \\
\text { hapus }\end{array}$ & $\begin{array}{c}\text { Klik } \\
\text { tomb } \\
\text { ol }\end{array}$ & $\begin{array}{c}\text { Sistem } \\
\text { akan } \\
\text { menghapus } \\
\text { data }\end{array}$ & $\begin{array}{c}\text { Sesuai } \\
\text { yang } \\
\text { diharapk } \\
\text { an }\end{array}$ & Valid \\
& & & & & \\
\hline
\end{tabular}

Tabel 4. Pengujian Black Box testing tampilan menu

\begin{tabular}{|c|c|c|c|c|c|}
\hline $\begin{array}{c}\text { No } \\
\text {. }\end{array}$ & $\begin{array}{c}\text { Skenario } \\
\text { Pengujian }\end{array}$ & $\begin{array}{l}\text { Test } \\
\text { Case }\end{array}$ & $\begin{array}{c}\text { Hasil } \\
\text { Yang } \\
\text { diharapka } \\
n\end{array}$ & Hasil uji & $\begin{array}{c}\text { Kesimpul } \\
\text { an }\end{array}$ \\
\hline 1. & $\begin{array}{c}\text { Menampilk } \\
\text { an menu }\end{array}$ & $\begin{array}{l}\text { Klik } \\
\text { icon } \\
\text { menu }\end{array}$ & $\begin{array}{c}\text { Sistem } \\
\text { akan } \\
\text { menampilk } \\
\text { an semua } \\
\text { menu yang } \\
\text { dapat } \\
\text { diakses } \\
\text { oleh guru }\end{array}$ & $\begin{array}{c}\text { Sesuai } \\
\text { yang } \\
\text { diharapk } \\
\text { an }\end{array}$ & Valid \\
\hline 2. & $\begin{array}{l}\text { Mengklik } \\
\text { menu } \\
\text { dashboard }\end{array}$ & $\begin{array}{c}\text { Klik } \\
\text { menu } \\
\text { dashboa } \\
\text { rd }\end{array}$ & $\begin{array}{c}\text { Sistem } \\
\text { akan } \\
\text { mengarahk } \\
\text { an } \\
\text { kehalaman } \\
\text { dashboard } \\
\text { guru }\end{array}$ & $\begin{array}{c}\text { Sesuai } \\
\text { yang } \\
\text { diharapk } \\
\text { an }\end{array}$ & Valid \\
\hline 3. & $\begin{array}{c}\text { Mengklik } \\
\text { menu } \\
\text { materi }\end{array}$ & $\begin{array}{c}\text { Klik } \\
\text { menu } \\
\text { materi }\end{array}$ & $\begin{array}{c}\text { Sistem } \\
\text { akan } \\
\text { mengarahk } \\
\text { an } \\
\text { kehalaman } \\
\text { materi }\end{array}$ & $\begin{array}{c}\text { Sesuai } \\
\text { yang } \\
\text { diharapk } \\
\text { an }\end{array}$ & Valid \\
\hline 4. & $\begin{array}{l}\text { Mengklik } \\
\text { menu tugas }\end{array}$ & $\begin{array}{l}\text { Klik } \\
\text { menu } \\
\text { tugas }\end{array}$ & $\begin{array}{c}\text { Sistem } \\
\text { akan } \\
\text { mengarahk } \\
\text { an } \\
\text { kehalaman } \\
\text { tugas }\end{array}$ & $\begin{array}{c}\text { Sesuai } \\
\text { yang } \\
\text { diharapk } \\
\text { an }\end{array}$ & Valid \\
\hline
\end{tabular}

Selain pengujian dengan Black Box testing dilakukan pula Pengujian Compability yaitu dengan Emulator android (AVD) adalah konfigurasi dari emulator sehingga kita dapat menjalankan perangkat Android sesuai model yang dipilih, misalkan Android 1.5 atau 2.2. Untuk dapat menjalankan emulator.[10]Pengujian ini dilakukan untuk mengetahui spesifikasi smartphone yang dapat menjalankan aplikasi $E$ Learning, terlihat pada tabel berikut:
Tabel 5. Uji Compability Ram 2GB, OS Lollipop

\begin{tabular}{|c|c|c|c|c|}
\hline No & $\begin{array}{c}\text { Merek } \\
\text { Smartphone }\end{array}$ & Berhasil & $\begin{array}{c}\text { Tidak } \\
\text { Berhasil }\end{array}$ & Keterangan \\
\hline 1 & Samsung & $\checkmark$ & - & $\begin{array}{c}\text { Aplikasi } \\
\text { berjalan }\end{array}$ \\
\hline 2 & Xiaomi & $\checkmark$ & - & $\begin{array}{c}\text { Aplikasi } \\
\text { berjalan }\end{array}$ \\
\hline 3 & Oppo & $\checkmark$ & - & $\begin{array}{l}\text { Aplikasi } \\
\text { berjalan }\end{array}$ \\
\hline 4 & Realme & $\checkmark$ & - & $\begin{array}{l}\text { Aplikasi } \\
\text { berjalan }\end{array}$ \\
\hline 5 & Asus & $\checkmark$ & - & $\begin{array}{l}\text { Aplikasi } \\
\text { berjalan }\end{array}$ \\
\hline 6 & Vivo & $\checkmark$ & - & $\begin{array}{l}\text { Aplikasi } \\
\text { berjalan }\end{array}$ \\
\hline 7 & Infinix & $\checkmark$ & - & $\begin{array}{l}\text { Aplikasi } \\
\text { berjalan }\end{array}$ \\
\hline
\end{tabular}

Hasil Pengujian dengan Black Box testing dan Pengujian Compability yaitu dengan Emulator android (AVD) sistem $100 \%$ berjalan dengan baik.

\section{KESIMPULAN}

Berdasarkan hasil penelitian yang telah dilakukan, maka dapat disimpulkan bahwa Perancangan kegiatan belajar mengajar pada aplikasi E-Learning di SMK Prisma Citra Nusantara berbasis android berhasil dilakukan, dengan menggunakan rancangan Use case Diagram, Activity Diagram, Class Diagram dan metode pengembangan Waterfall, serta implementasi aplikasi di era pandemi saat ini sangatlah di anjurkan, karena dengan adanya aplikasi ini siswa dan guru dapat berinteraksi secara daring, aplikasi ini bersifat private user dalam artian hanya siswa, guru serta admin di SMK saja yang terlibat dalam aplikasi ini.

\section{V.SARAN}

Dalam pengembangan sistem informasi kegiatan belajar mengajar pada aplikasi E-Learning di SMK Prisma Citra Nusantara berbasis android masih ada beberapa hal bisa dikembangkan seperti Untuk meningkatkan pengembangan sistem informasi kegiatan belajar mengajar pada aplikasi $E$ Learning berbasis android lebih baik, pihak sekolah harus mensosialisasikan kepada murid, guru dan ataupun wali murid. Untuk peneliti diharapkan untuk mengembangkan sistem informasi yang lebih baik, karena dalam aplikasi E-Learning di SMK Prisma Citra Nusantara berbasis android ini masih memiliki kekurangan lainnya.

\section{REFERENSI}

[1] H. Wibowo, E. N. Susanti, and R. Rizky, "Implementasi Mobile Learning Berbasis Android Untuk Pembelajaran Teknik Pengambilan Gambar 
Bergerak Pada Jurusan Multimedia," vol. 8, no. 2, pp. 146-154, 2020.

[2] M. Praseptiawan, D. Sujana, and M. Djuanda, "Pengembangan Mobile Learning (M-learning) STKIP Setia Budi Sebagai Daya Dukung Pembelajaran Mahasiswa," J u r n a l P R O D U K T I F, vol. 2, pp. 13-18, 2018.

[3] F. Septiawan, "the Effectiveness of the Use of Google Form in Linear Learning in Motorcycle Maintenance Lessons in Smkn 1 Koba," J. Pendidik. Tek. Mesin, vol. 7, no. 2, pp. 129-135, 2020.

[4] D. Febriannisa and L. P. Hasugian, "Perancangan $E$ Learning pada SMK Negeri 1 Bandung," J. Ultim. InfoSys, vol. 8, no. 2, pp. 62-68, 2018, doi: 10.31937/si.v8i2.613.

[5] Dina Maulina and Bernadhed, "PERANCANGAN SISTEM INFORMASI E-LEARNING PADA SMK SYUBBANUL WATHON TEGALREJO MAGELANG," J. Ilm. DASI, vol. 18, no. 1, pp. 8-13, 2017, [Online]. Available: https://ojs.amikom.ac.id/index.php/dasi/article/view/1 $827 / 1549$.

[6] T. A. Kurniawan, "Pemodelan Use case (UML): Evaluasi Terhadap beberapa Kesalahan dalam Praktik," J. Teknol. Inf. dan Ilmu Komput., vol. 5, no. 1, p. 77, 2018, doi: 10.25126/jtiik.201851610.

[7] M. K. Hidayat and R. C. P. Ningrum, "Sistem Informasi Penjualan Online Pada Toko Yusuf Bekasi," Sist. Inf. Penjualan Online Pada Toko Yusuf Bekasi, vol. 2, no. 2, pp. 24-30, 2015.

[8] Ade Hendini, "Pemodelan Uml Sistem Informasi Monitoring Penjualan Dan Stok Barang (Studi Kasus: Distro Zhezha Pontianak)," J. KHATULISTIWA Inform., vol. IV, no. 2, pp. 107-116, 2016, doi: https://doi.org/10.31294/jki.v4i2.1262.

[9] L. Setiyani, "Pengujian Sistem Informasi Inventory Pada Perusahaan Distributor Farmasi Menggunakan Metode Black Box Testing," Techno Xplore J. Ilmu Komput. dan Teknol. Inf., vol. 4, no. 1, pp. 1-9, 2019, doi: 10.36805/technoxplore.v4i1.539.

[10] Y. P. Harison, Busran, "Aplikasi Education Bahasa Inggris Yang Bisa Diatur Sebagai Alat Pengukur Kemampuan Penguasaan Kosakata Berbasis Android," J. Ipteks Terap., vol. 9, no. 3, pp. 195-200, 2015, doi: 10.22216/jit.2015.v9i3.418. 